Revista Brasileira de Cartografia

ISSN 1808-0936 | https://doi.org/10.14393/revbrascartogr

Sociedade Brasileira de Cartografia, Geodésia, Fotogrametria e Sensoriamento Remoto

\title{
Avaliação de Imagens Obtidas com o Sensor Micasense na Estimativa da Batimetria em Corpos D’água Opticamente Rasos
}

\section{Evaluation of Images Obtained with the Micasense Sensor to Estimate Bathymetry in Optically Shallow Water}

Laura Coelho de Andrade ${ }^{1}$, Italo Oliveira Ferreira ${ }^{2}$, Nilcilene das Graças Medeiros ${ }^{3}$, Victória Gibrim Teixeira ${ }^{4}$ e Felipe Catão Mesquita Santos ${ }^{5}$

1 Universidade Federal de Viçosa, Departamento de Engenharia Civil, Viçosa, Brasil. laura.andrade@ufv.br ORCID: https://orcid.org/0000-0003-3693-2208

2 Universidade Federal de Viçosa, Departamento de Engenharia Civil, Viçosa, Brasil. italo.ferreira@ufv.br ORCID: https://orcid.org/0000-0002-4243-8225

3 Universidade Federal de Viçosa, Departamento de Engenharia Civil, Viçosa, Brasil. nilcilene.medeiros@ufv.br ORCID: https://orcid.org/0000-0003-0839-3729

4 Universidade Federal de Viçosa, Departamento de Engenharia Civil, Viçosa, Brasil. victoria.gibrim@ufv.br ORCID: https://orcid.org/0000-0002-7279-110X

5 Universidade Federal de Viçosa, Departamento de Engenharia Civil, Viçosa, Brasil. felipe.mesquita@ufv.br ORCID: https://orcid.org/0000-0002-9376-766X

Recebido: 06.2020 | Aceito: 10.2020

Resumo: O levantamento batimétrico é parte integrante do estudo da hidrografia e consequentemente dos corpos d'água existentes. Ultimamente, tem sido notória a disseminação da importância da preservação dos corpos hídricos existentes no planeta. Nesse âmbito, os levantamentos batimétricos são a peça chave para o cálculo do assoreamento ao longo dos anos, estimativa de volume, erosão nas bordas, cálculo dos sedimentos em suspensão, dentre outros. Esses estudos são realizados, usualmente, por meio de ecobatímetros, os quais utilizam da onda sonora para obtenção da profundidade. Todavia, os levantamentos com esses equipamentos são demorados e na maioria das vezes possuem um custo elevado. Dessa forma, com o avanço tecnológico, inúmeros trabalhos nessa área já foram feitos com dados de sensoriamento remoto, muitos utilizando imagens orbitais. Com o surgimento dos RPA's (Remotely Pilot Aircraft), incontáveis benefícios para o mapeamento costeiro podem ser obtidos, principalmente no quesito agilidade. Diante do exposto, o presente estudo tem como objetivo principal a avaliação da estimativa da batimetria obtida com o sensor multiespectral Micasense vinculado a uma aeronave autônoma não tripulada. Os resultados encontrados mostraram que a metodologia descrita, em conjunto com o sensor escolhido, pode ser empregada em diversos estudos de cunho ambiental ou que objetivam a melhor gestão de recursos hídricos, sobretudo em águas límpidas. Todavia, deve-se existir alguns cuidados principalmente na execução do levantamento aerofotogramétrico, atentando-se para o fato de que diferentes locais irão conter diferentes taxas de componentes opticamente ativos e consequentemente resultados distintos.

Palavras-chave: Levantamento Batimétrico. RPA. Sensoriamento Remoto.

\begin{abstract}
The bathymetric survey is an integral part of the study of hydrography and consequently of the existing water bodies. Lately, the dissemination of the importance of preserving existing water bodies on the planet has been well known. In this context, bathymetric surveys are the key to calculating silting over the years, estimating volume, erosion at the edges, calculating suspended sediments, among others. These studies are usually performed using echo sounders, which use the sound wave to obtain depth. However, these are time consuming and most of the time have a high cost. Thus, with technological advances, numerous works in this area have already been done with orbital images and the emergence of RPA's (Remotely Pilot Aircraft) systems coupled to aircraft, has brought countless benefits for coastal mapping in the agility, but still not showing efficiency in the cost issue. In view of these issues raised, the present study has as main objective the evaluation of the bathymetry estimate obtained with the Micasense multispectral sensor linked to an unmanned autonomous aircraft. The results found showed that the methodology described, together with the chosen sensor, can be used in several studies of an environmental nature or that aim at the better management of water resources, mainly in clear waters. However, there must be some cautions, especially during the execution of the aerial photogrammetric survey, with attention to the fact that different locations will contain different rates of Optically Active Components and consequently different results.

Keywords: Bathymetric survey. RPA. Remote sensing.
\end{abstract}




\section{INTRODUÇÃO}

O controle do volume de água em reservatórios e demais corpos hídricos interiores do continente pode fornecer informações essenciais sobre o assoreamento do local, bem como estimativa do volume para gestão do abastecimento público, irrigação, monitoramento, entre outros e, por conseguinte, evitar possíveis falhas no abastecimento hídrico da população. Atualmente, ainda existe o cálculo do volume de reservatórios artificiais por meio de cartas topográficas antes do enchimento, todavia, esse método está caindo em desuso. Normalmente, o cálculo do volume é realizado por meio das profundidades coletadas em levantamentos batimétricos, os quais na maioria das vezes empregam o princípio da propagação da onda sonora na água através dos equipamentos chamados ecobatímetros. Esses podem ser de feixe único ou multifeixe e são tradicionalmente empregues em conjunto com sistemas de posicionamento planimétrico, como o Global Navigation Satellite System (GNSS) para o georreferenciamento das profundidades e até mesmo sensores inerciais para o controle dos movimentos da embarcação (IHO, 2005; JONG et al., 2010; FERREIRA; RODRIGUES; SANTOS, 2015).

O progresso tecnológico propiciou o surgimento de inúmeros veículos autônomos para realização da sondagem batimétrica, exemplo disso são os Unmanned Surface Vehicle (USV), Autonomus Surface Craft (ASC) ou Autonomus Surface Vehicle (ASV) que além de exigirem um menor tempo para o levantamento, também são úteis para locais que oferecem risco a tripulação ou são de baixa profundidade (MANLEY, 2008; GIORDANO et al., 2015; FERREIRA; AYRES NETO; MONTEIRO, 2016).

Tal como a criação de novos equipamentos que se utilizam da onda sonora para obtenção da profundidade, também foi notório o surgimento dos sistemas Light Detection And Ranging (LiDAR) no âmbito hidrográfico (GUENTHER et al., 1996; PASTOL, 2011; ELLMER et al., 2014), os quais se utilizam das ondas eletromagnéticas para estimar a batimetria de áreas rasas e costeiras, e funcionam como um sensor ativo (irradiam uma energia artificial para o monitoramento, sem necessitar da luz solar). Esse sistema proporcionou uma produtividade ainda maior do levantamento, todavia sua utilização fica restrita devido aos altos custos relacionados ao sobrevoo e à algumas questões associadas a profundidade máxima de operação, turbidez da água, nível de incerteza das profundidades calculadas e identificação de objetos.

O uso de imagens orbitais para estimativa da batimetria também foi um acontecimento possibilitado pela ascensão tecnológica. Por meio de técnicas de obtenção da batimetria por resposta espectral, diversos autores estimaram profundidades em corpos hídricos, obtendo resultados satisfatórios para os fins pretendidos. Basicamente, os autores utilizaram índices e equações que identificam e correlacionam o melhor comportamento espectral dos canais existentes nas imagens com as profundidades (MARITORENA et al., 1994; KRUG; NOERNBERG, 2007; ZANI et al., 2009; GAUTAUM et al., 2015; FERREIRA et al., 2016; COLLISCHONN; CLARKE, 2016).

Dentre os índices supracitados comumente é aplicado o Normalized Difference Water Index (NDWI) para a delimitação de corpos d'água, a partir de combinações de bandas como da luz verde e o infravermelho próximo (LI, 2013). Esse tal índice foi a priori proposto por Mcfeeters (1996), que tinha como objetivo aproveitar a elevada reflexão da região do infravermelho próximo (NIR) para a vegetação e solo, minimizando a baixa reflexão da água. Krug e Noernberg (2007) empregaram o sistema Landsat para estimar a batimetria em águas rasas com o uso do NDWI e obtiveram resultados otimistas. Zani et al.(2009) realizaram um estudo no rio Paraguai com o sensor ASTER e obtiveram um desvio padrão da amostra de 0,36 metros. Foerstnow (2011) realizou um estudo na Lagoa da Conceição em Florianópolis - SC, o qual aplicou o índice e dividiu a área de estudo de acordo com a profundidade, dessa forma o autor concluiu que o intervalo que conferia uma melhor correlação com a batimetria seria em profundidades de 1 a 5 metros. Gautaum et al. (2015) verificaram vários índices para avaliação da existência de água em Bangalore na Índia. Ferreira et al. (2016) utilizaram imagens do satélite RapidEYE e também o índice NDWI para estimativa da profundidade de um reservatório situado em Viçosa - MG e encontraram a maioria das discrepâncias menores que 1 metro. Autores como Collischonn e Clarke (2016) criaram uma metodologia baseada em imagens de satélite para estimativa e 
verificação da curva cota-área-volume de um reservatório em Minas Gerais e concluíram que a precisão encontrada é diretamente proporcional à qualidade do sistema e sensor utilizado.

O produto que resulta desse tipo de estudo, bem como em um levantamento batimétrico tradicional, consiste em vários pontos espaçados que não permitem a representação do fundo submerso de forma espacialmente contínua e, por conseguinte, prejudica também o observador a fazer determinadas análises sobre o resultado gerado. Assim, recomenda-se a utilização de interpoladores para aferir o valor da profundidade em locais não amostrados, gerando um modelo batimétrico (CAMARGO, 1998; FERREIRA; RODRIGUES; SANTOS, 2013). Dentre os tipos de interpoladores para representação de relevos submersos, têm-se observado uma preferência por interpoladores probabilísticos, especialmente a Krigagem Universal (KU), que possibilita modelar a dependência espacial da variável profundidade, com variância mínima e sem viés (FERREIRA; RODRIGUES; SANTOS, 2013; ANDRADE et al., 2018). Valeriano et al. (2006) aplicaram metodologia similar para modelagem de dados topográficos e constataram que a krigagem eliminou diversos componentes indesejados, mantendo a acurácia dos dados.

O advento das aeronaves autônomas não tripuladas, conhecidas popularmente como drones e tecnicamente como Veículos Autônomos Não Tripulados (VANT's) ou Remotely Pilot Aircrafts (RPA's), acopladas com sensores RGB ou multiespectrais, permite vários estudos nessa área, estabelecendo uma correlação por meio de uma equação exponencial ou logarítmica entre a profundidade e as respostas espectrais - técnica conhecida como Batimetria Por Resposta Espectral. O fato da aeronave estar situada a alguns metros do solo, possibilita a exclusão de vários efeitos indesejados advindos da atmosfera, como espalhamentos e demais interferências de absorção de gases atmosféricos (POLIDORIO et al., 2005).

Sendo assim, em primeiro instante, no caso da batimetria, poucos estudos foram desenvolvidos sobre o emprego desses sensores nesta área, implicando em questões ainda não respondidas, como, por exemplo, em seu desempenho em termos de precisão na obtenção das profundidades, a integração de seu uso com outros sensores, bem como na agilidade do processo de levantamento dos dados.

Andrade et al. (2020) concluíram que sensores infravermelhos podem ser utilizados para fornecer insumos para estudos preliminares em corpos d'água rasos acerca da morfologia do fundo de um reservatório e também para estudos ambientais. Como proposto por esses mesmos autores, a utilização de diferentes sensores na aquisição de imagens pode influenciar diretamente no produto final, ou seja, no modelo digital de profundidade e também nas suas incertezas.

Assim, o principal objetivo deste estudo consiste em avaliar a estimativa da batimetria obtida com o sensor multiespectral Micasense vinculado a uma aeronave autônoma não tripulada. Seguindo a metodologia fundamentada na junção de dados batimétricos adquiridos com ecobatímetro de feixe único e imagens de RPA's, com intuito de obter a estimativa da profundidade e volume do reservatório a um custo menor e também com um tempo de execução reduzido. Ao final também foram executadas análises robustas das discrepâncias resultantes do modelo digital encontrado por meio do algoritmo MAIB (FERREIRA, 2018).

\section{FUNDAMENTAÇÃO TEÓRICA}

\subsection{Retificação Diferencial}

A retificação é o processo de obtenção de fotografias verticais a partir de fotografias inclinadas. As fotos retificadas em teoria são fotos verdadeiramente verticais e, dessa forma, estão livres de deslocamentos na imagem devido às inclinações da plataforma. No entanto, ainda contêm deslocamentos na imagem devido ao relevo topográfico. Esses deslocamentos de relevo podem ser removidos em um processo de retificação diferencial ou ortorretificação, e os produtos resultantes são chamados de ortofotos (WOLF; DEWITT, 2000) (Figura 1). 
Figura 1 - Exemplo do processo de ortorretificação em uma imagem.

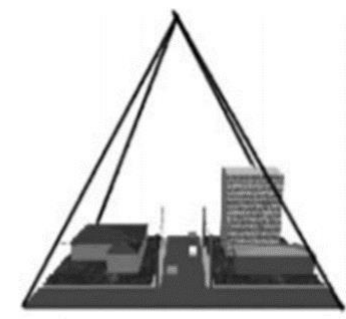

Perspectiva Central

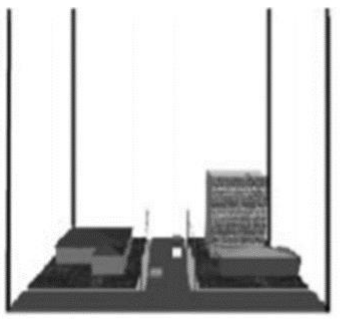

Perspectiva Ortogonal
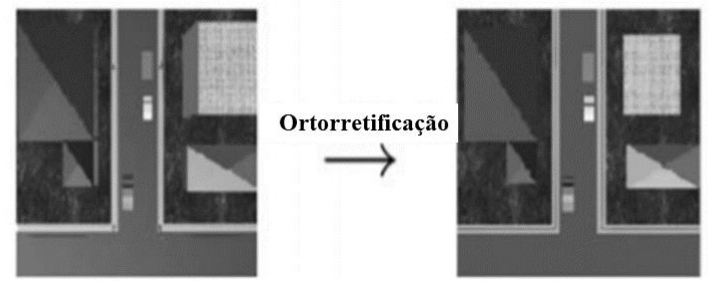

Fonte: Coelho e Britto (2007).

A ortorretificação é feita através de transformações matemáticas nos números digitais dos pixels das imagens. Essas transformações podem ser Afim, Projetiva ou a Retificação Diferencial (COELHO; BRITTO, 2007).

A Retificação Diferencial é o método mais genérico e também o mais usado, uma vez que são obtidos os melhores resultados. O intuito dessa ferramenta consiste em gerar uma nova imagem ortogonal, por meio da reconstrução dos feixes perspectivos que formaram a cena imageada.

Para isso, de acordo com Coelho e Britto (2007) faz-se necessário a definição de uma ortomatriz vazia sobre o terreno imageado para realização dessa técnica. Essa ortomatriz é correlacionada a uma imagem digital "em branco", cujo pixels possuem dimensões da mesma ordem do elemento de resolução do terreno. Após, são encontradas as coordenadas X, Y e Z conhecidas do centro de cada pixel da ortomatriz inicial, com uso do Modelo Numérico de Elevação e são definidas as coordenadas no espaço-imagem para cada ponto, por meio dos parâmetros de orientação exterior já conhecidos. A partir dos parâmetros da orientação interior é possível encontrar o pixel e seu nível de cinza na imagem bruta. Na Figura 2 esse processo é representado.

Figura 2 - Processo de ortorretificação por meio de retificação diferencial.

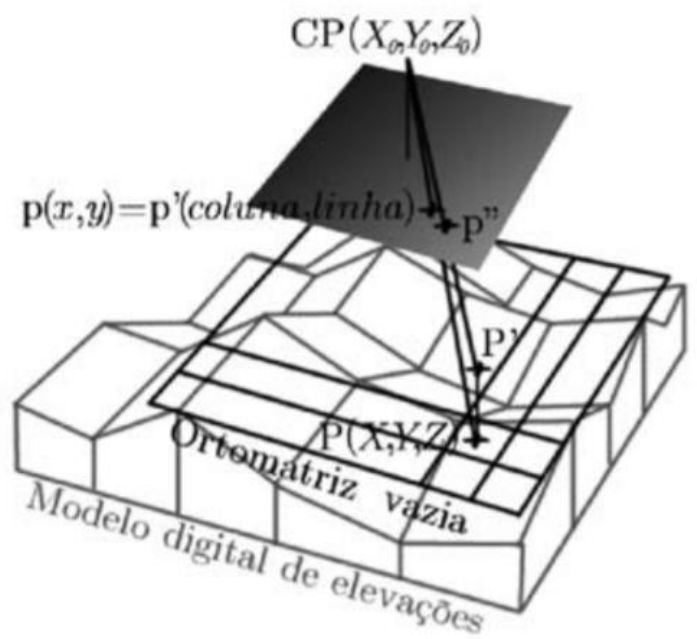

Fonte: Coelho e Britto (2007).

Segundo Schenk (2005), apenas uma fotografia retificada diferencialmente, ou seja, uma ortofoto, é geometricamente correspondente a um mapa. 


\subsection{Geoestatística}

A Geoestatística é bastante utilizada em situações de dependência espacial, sendo baseada na Teoria das Variáveis Regionalizadas. De acordo com Vieira (2000) e Batista (2012), essa ferramenta emprega funções numéricas mais complexas que variam espacialmente com uma continuidade capaz de ser confirmada pelo semivariograma.

O semivariograma é uma ferramenta inserida na Geoestatística, que serve de suporte às técnicas de interpolação pelos métodos da krigagem (FERREIRA; RODRIGUES; SANTOS, 2013), uma vez que por meio desse instrumento é possível modelar a dependência espacial, efetuando o ajuste de um modelo teórico visando estimar os parâmetros denominados efeito pepita, contribuição, patamar e alcance que melhor se encaixam com semivariograma experimental dos dados que foram observados. A Figura 3 apresenta dois semivariogramas: na esquerda com dados dependentes e na direita com dados independentes espacialmente (caracterizado pelo efeito pepita puro).

Figura 3 - Ilustração de semivariograma experimentais: (a) Amostra dependente e (b) Amostra independente.

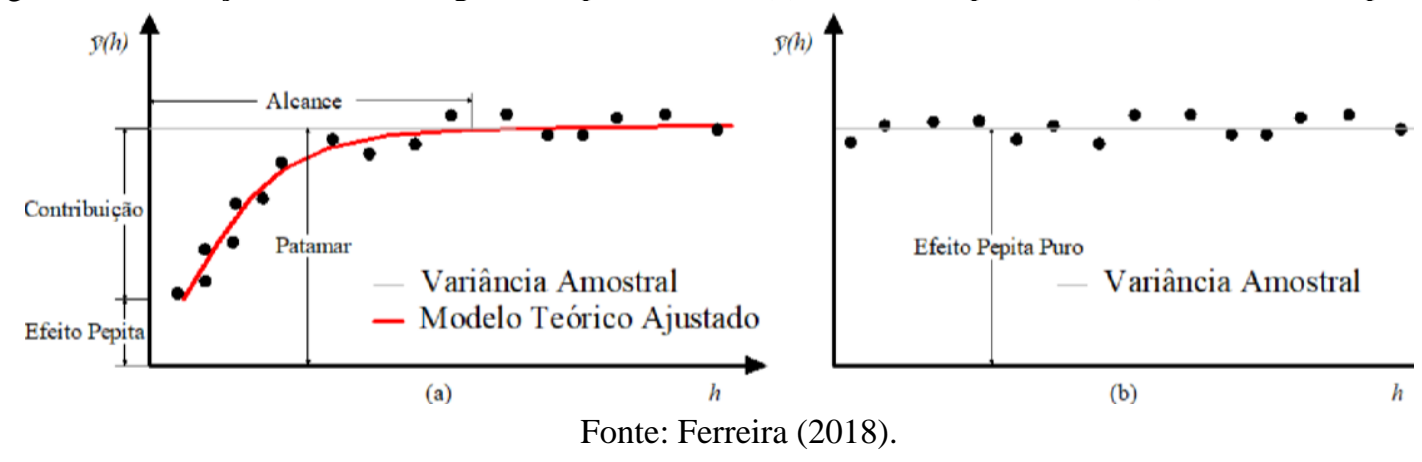

Após a modelagem, existe o processo de validação cruzada, o qual retira um valor amostrado de forma temporária e prediz o valor do mesmo a partir do modelo teórico ajustado com os outros valores amostrados (FERREIRA, 2018). Assim é possível avaliar a qualidade da estimativa, por meio da verificação das diferenças entre os valores preditos e os observados.

\subsection{Métodos de regressão}

A regressão é uma ferramenta da estatística que possibilita explorar e inferir a relação de uma variável com outra. $\mathrm{Na}$ atualidade existem três métodos de regressão, sendo eles regressão linear simples, múltipla e não linear.

Com o intuito de encontrar uma equação que represente o fenômeno em estudo, pode-se construir um diagrama de dispersão para analisar como os valores da variável dependente $\mathrm{Y}$ se comportam em função da variável independente. Esse diagrama pode ser linear, quadrático, cúbico, exponencial, logarítmico e etc. (BELSLEY; KUH; WELSCH, 1980) e a curva que mais se aproximar da localização espacial dos pontos será o modelo que poderá explicar o fenômeno. Como exemplo, na Eq. (1), é demonstrada a equação resultante de uma regressão linear simples.

$$
Y=\beta 0+\beta 1 . X
$$

Ainda nesse contexto existe o coeficiente de determinação, representado pelo $\mathrm{R}^{2}$, o qual verifica a relação entre as variáveis, analisando se o modelo proposto é adequado ou não para descrever o fenômeno. Essa ferramenta auxiliar varia de 0 a 1 . Valores mais próximos de 1 evidenciam que o modelo proposto é adequado para descrever o fenômeno, indicando a porcentagem da variação de Y (como na Eq. (1)) que é explicada por X (SEBER, 1977; DRAPER; SMITH, 1981). 


\section{METODOLOGIA DO TRABALHO}

\section{1 Área de estudo}

A área de estudo escolhida para o desenvolvimento do estudo é um dos principais reservatórios da Universidade Federal de Viçosa (lagoa das quatro pilastras), situado na cidade de Viçosa - MG, compreendido entre as coordenadas $20^{\circ} 45^{\prime} 25^{\prime \prime} \mathrm{S}$ e $20^{\circ} 45^{\prime} 40^{\prime \prime} \mathrm{S}$ de latitude e $42^{\circ} 52^{\prime} 15^{\prime \prime} \mathrm{O}$ e $42^{\circ} 52^{\prime} 30^{\prime \prime} \mathrm{O}$ de longitude (Figura 4). Este possui atualmente uma profundidade média de 3,5 metros, mínima de 0 metros e máxima de 4,39 metros, mas está em processo constante de assoreamento, assim como os demais corpos d'água presentes no campus. Ressalta-se que in loco é notória a presença de sedimentos em suspensão, assim como plantas aquáticas por toda área.

Figura 4 - Área de Estudo.

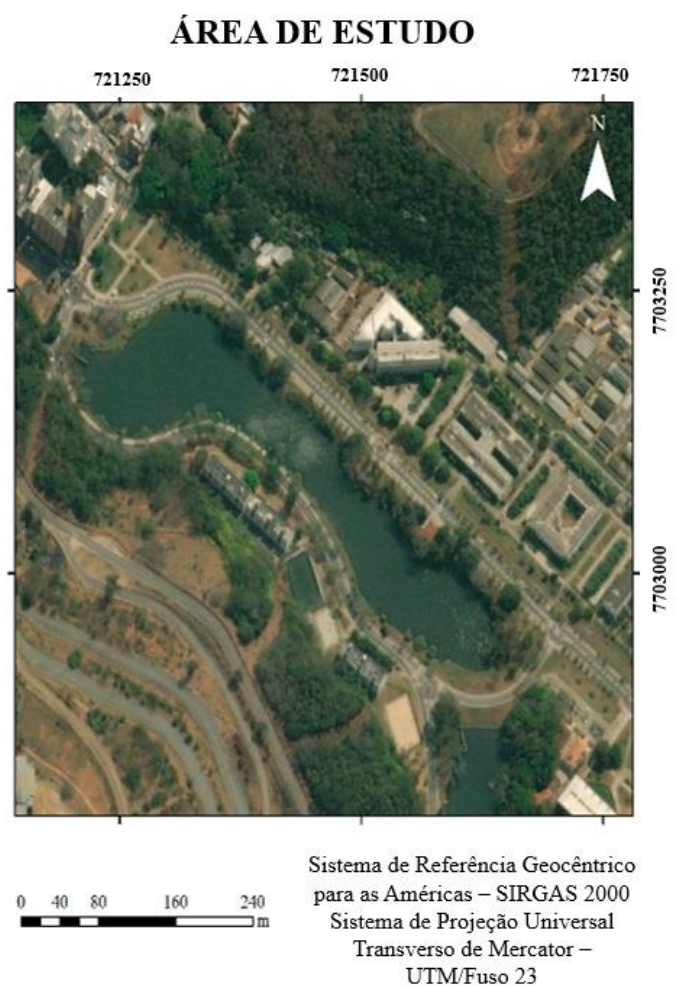

Fonte: Os autores (2021).

Salienta-se também a importância socioeconômica do local para todo o município de Viçosa - MG, uma vez que a lagoa em questão funciona como uma área de lazer para moradores locais, estudantes e turistas.

\subsection{Metodologia}

Para um melhor entendimento da metodologia abordada, apresenta-se um fluxograma (Figura 5), baseado em Andrade et al. (2020). 
Figura 5 - Fluxograma da metodologia.

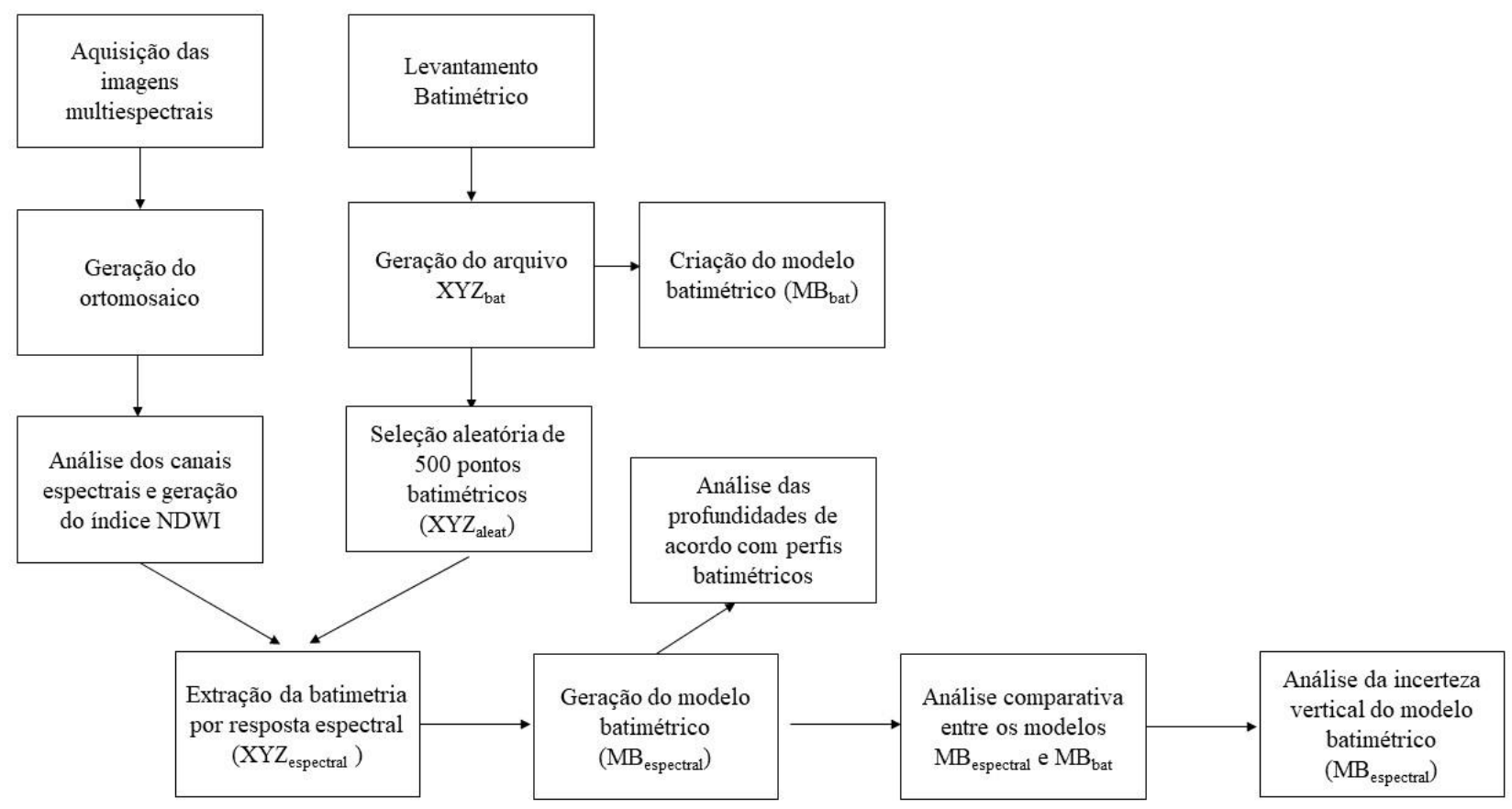

Fonte: Os autores (2021).

\subsubsection{AQUISIÇÃO DAS IMAGENS MULTIESPECTRAIS E GERAÇÃO DO ORTOMOSAICO}

As imagens multiespectrais foram obtidas com o uso do sensor Micasense RedEdge-MX (MICASENSE, 2020) acoplada ao drone multirotor Phantom 4. As principais características do sensor podem ser verificadas na Tabela 1 . O voo cobriu todo o local de estudo, a uma altura de aproximadamente 120 metros com uma duração média de quatro minutos, sobreposição longitudinal de $85 \%$ e lateral de $70 \%$, totalizando 664 cenas obtidas. É importante ressaltar que as imagens resultantes do voo têm uma resolução radiométrica de 16 bits e espacial de $8 \mathrm{~cm}$.

Tabela 1 - Principais características do sensor Micasense RedEdge-MX.

\begin{tabular}{|c|c|c|c|c|c|c|c|c|c|c|}
\hline Peso & Dimensões & $\begin{array}{c}\text { Bandas } \\
\text { espectrais }\end{array}$ & \multicolumn{5}{|c|}{ Comprimento de onda (nm) } & $\begin{array}{c}\text { Distância } \\
\text { da } \\
\text { amostra } \\
\text { do solo } \\
\text { (GSD) } \\
\end{array}$ & $\begin{array}{l}\text { Taxa de } \\
\text { captura }\end{array}$ & $\begin{array}{c}\text { Campo } \\
\text { de } \\
\text { visão }\end{array}$ \\
\hline $231,9 \mathrm{~g}$ & $\begin{array}{c}8,7 \mathrm{~cm} \mathrm{x} \\
5,9 \mathrm{~cm} \mathrm{x} \\
4,54 \mathrm{~cm}\end{array}$ & $\begin{array}{c}\text { Azul, } \\
\text { verde, } \\
\text { vermelho, } \\
\text { red edge e } \\
\text { infraverm } \\
\text { elho } \\
\text { próximo } \\
\text { (NIR) }\end{array}$ & $\begin{array}{c}\text { Azul } \\
(475 \mathrm{~nm})\end{array}$ & $\begin{array}{c}\text { Verde } \\
(560 \mathrm{~nm})\end{array}$ & $\begin{array}{l}\text { Vermelho } \\
(668 \mathrm{~nm})\end{array}$ & $\begin{array}{c}\text { Red Edge } \\
(717 \mathrm{~nm})\end{array}$ & $\begin{array}{c}\text { NIR } \\
(840 \mathrm{~nm})\end{array}$ & $\begin{array}{l}8 \mathrm{~cm} \text { a } 120 \\
\mathrm{~m} \text { de altura }\end{array}$ & $\begin{array}{c}1 \text { captura } \\
\text { por } \\
\text { segundo } \\
\text { (todas as } \\
\text { bandas), } \\
\text { RAW de } \\
12 \text { bits }\end{array}$ & $\begin{array}{l}47.2^{\circ} \\
\text { HFOV }\end{array}$ \\
\hline
\end{tabular}

Fonte: Micasense (2020).

Adiante, foi executado o processamento das imagens e, por conseguinte, a geração do ortomosaico no software Agisoft Metashape 1.5 (METASHAPE, 2018). Na geração do ortomosaico, para a eliminação dos erros sistemáticos advindos das distorções existentes acarretadas no momento da tomada das fotografias, foi realizada a correção geométrica por meio de algoritmos fotogramétricos de ortorretificação diferencial, com uso de sete pontos de controle, situados ao entorno da área de estudo (Figura 6). 
Figura 6 - Distribuição dos pontos de controle.

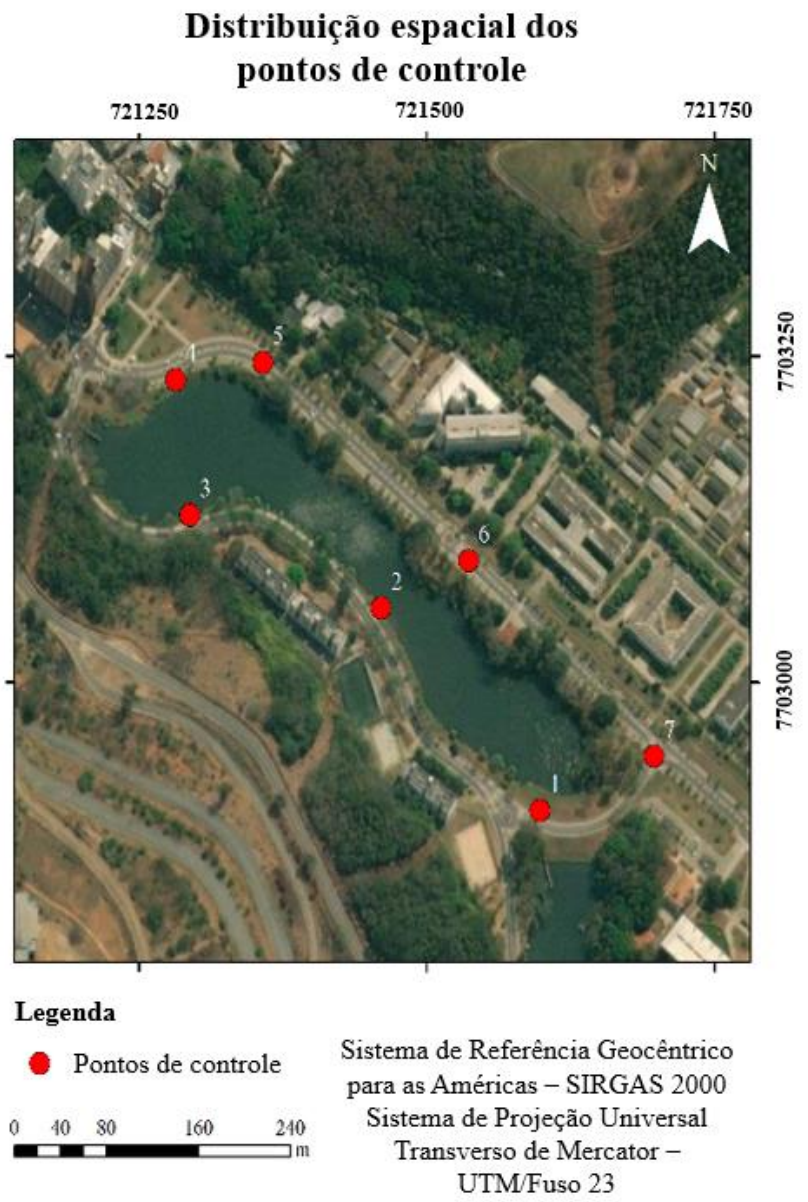

Fonte: Os autores (2021).

Sete pontos de checagem foram utilizados para verificação do produto final gerado. Tais pontos, tanto de controle como checagem, foram coletados através do sistema GNSS Trimble R10 (CROSTA, 1999). Destaca-se que foi utilizada a projeção cartográfica UTM, fuso $23 \mathrm{~S}$ referenciada no sistema geodésico SIRGAS2000.

De acordo com Menezes e Almeida (2012), alguns estudos já comprovaram que a correção geométrica de imagens está totalmente correlacionada com a topografia da região e com a designação do produto final.

\subsubsection{ANÁLISE DOS CANAIS ESPECTRAIS E GERAÇÃO DO ÍNDICE NDWI}

Sabendo-se que o sensor empregado possui cinco canais espectrais, azul $(475 \mathrm{~nm})$, verde $(560 \mathrm{~nm})$, vermelho $(668 \mathrm{~nm})$, red-edge $(717 \mathrm{~nm})$ e NIR $(840 \mathrm{~nm})$, foi necessária uma análise minuciosa dos canais espectrais no software ArcGIS 10.5 (ESRI, 2019) para que se efetuasse uma verificação adequada do comportamento espectral dos alvos.

Frequentemente é apresentado na literatura métodos que visam a obtenção de dados batimétricos por resposta espectral, dentre esses existem aqueles que utilizam valores de radiância e outros que usam do nível digital para a estimativa da profundidade (TEDESCO; CENTENO, 2003). A lei de Beer's apresenta-se como o estudo inaugural nesse âmbito, exemplificando o ingresso da luz na coluna d'água por meio da absorção e espalhamento (LYZENGA, 1978; PHILPOT, 1989).

Nesse estudo, adotou-se como algoritmo de derivação da batimetria a partir de imagens obtidas por RPA's o índice proposto por McFeeters (1996), chamado NDWI, o qual realça o contraste existente entre a água e a cobertura vegetal. Esse índice é equacionado da seguinte forma (Eq. (2)):

$$
N D W I=\frac{\rho(G)-\rho(N I R)}{\rho(G)+\rho(N I R)}
$$


Em que $\rho(G)$, da Equação 2, corresponde ao intervalo espectral da luz verde do espectro visível (560 $\mathrm{nm})$, e $\rho(\mathrm{NIR})$ o intervalo espectral correspondente a região do infravermelho próximo ( $840 \mathrm{~nm})$.

Esse índice faz o uso desses intervalos espectrais, mais especificamente, para eliminar a influência do solo e vegetação no corpo d'água.

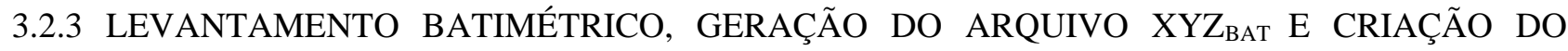 MODELO MB BAT}

Além disso, foi realizado um levantamento batimétrico próximo a data do voo, seguindo as normas propostas pela ANA-ANEEL (2010). Foi utilizado o sistema autônomo Echoboat-ASV, que é composto por um ecobatímetro monofeixe equipado por um transdutor com frequência central de $200 \mathrm{kHz}$ para obtenção da profundidade. Utilizou-se do nível da água local como nível de redução. Já para aquisição das coordenadas geodésicas planimétricas, foi empregue um receptor GNSS com correção diferencial da Atlas Link. A coleta e processamento dos dados foi efetuada no software Hypack (HYPACK, 2018), o que resultou em um arquivo de dados contendo as coordenadas $\mathrm{X}, \mathrm{Y}$ e $\mathrm{Z}$ dos pontos $\left(\mathrm{XYZ}_{\mathrm{bat}}\right)$. A partir desse momento, pode ser gerado o

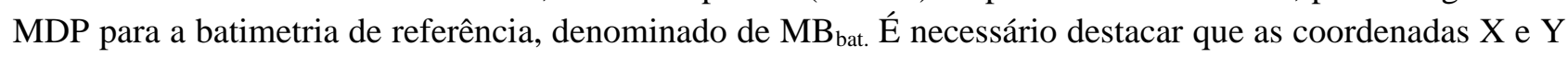
se referem respectivamente a Este e Norte das coordenadas UTM, já como Z considera-se a profundidade do local.

\subsubsection{SELEÇÃO ALEATÓRIA DE PONTOS BATIMÉTRICOSE, EXTRAÇÃO DA BATIMETRIA, GERAÇÃO DE MODELO ESPECTRAL E ANÁLISE DAS PROFUNDIDADES}

Posteriormente, foram selecionados 500 pontos de dados batimétricos para a criação da equação de correlação, através do modelo de regressão que melhor se encaixasse com os dados, entre os valores obtidos com o índice NDWI e as profundidades, no software Excel $\left(\mathrm{XYZ}_{\text {aleat }}\right)$. Por conseguinte, a equação encontrada foi empregada para estimar a batimetria da lagoa, gerando um arquivo $\mathrm{XYZ}_{\text {espectral. }}$ Em um segundo momento, foi efetuada a criação do MDP para a batimetria espectral $\left(\mathrm{MB}_{\text {espectral }}\right)$. $\mathrm{O}$ interpolador krigagem foi testado entre seus métodos simples e universal, sendo o universal apontado como mais apropriado para esse tipo de dado, como evidenciado por Ferreira, Rodrigues e Santos (2013), Andrade et al. (2018) e Santos et al. (2018). Com o intuito de fornecer uma análise completa e integrada sobre a profundidade da lagoa, também foram avaliadas três seções batimétricas na lagoa, comparando vários pontos de profundidade de referência e estimada.

\subsubsection{ANÁLISE COMPARATIVA DOS MODELOS E ANÁLISE DA INCERTEZA VERTICAL DE MB $_{\text {ESPECTRAL }}$}

Para uma análise comparativa entre os modelos $\mathrm{MB}_{\text {espectral }}$ o $\mathrm{MB}_{\text {bat, }}$ foi construído no software ArcGIS 10.5 (ESRI, 2019), um mapa de discrepâncias, subtraindo os valores estimados com o índice NDWI e aqueles coletados de forma tradicional. Além disso, também foram calculados os volumes para os respectivos modelos descritos.

Com o intuito de verificar a incerteza vertical do modelo gerado, foram selecionados um novo universo amostral de pontos da batimetria de referência diminuídos da batimetria estimada, para uma análise estatística. Optou-se por empregar a metodologia desenvolvida e proposta por Ferreira et al. (2018), chamada MAIB em ambiente R (R CORE TEAM, 2020).

\section{RESULTADOS}

A partir dos valores digitais obtidos do ortomosaico foi gerado o índice NDWI e, por conseguinte, esse foi correlacionado com a amostra $\mathrm{XYZ}_{\text {aleat }}$. Assim, obteve-se o modelo de regressão logarítmica representado na Figura 7, com a equação que mais se ajustou ao esse modelo e um coeficiente de determinação $\left(\mathrm{R}^{2}\right)$ de 
0,727, evidenciando que aproximadamente $70 \%$ da variação de resposta espectral pode ser caracterizada pelo modelo.

Figura 7 - Comportamento dos valores digitais representados pelo NDWI em relação a profundidade.

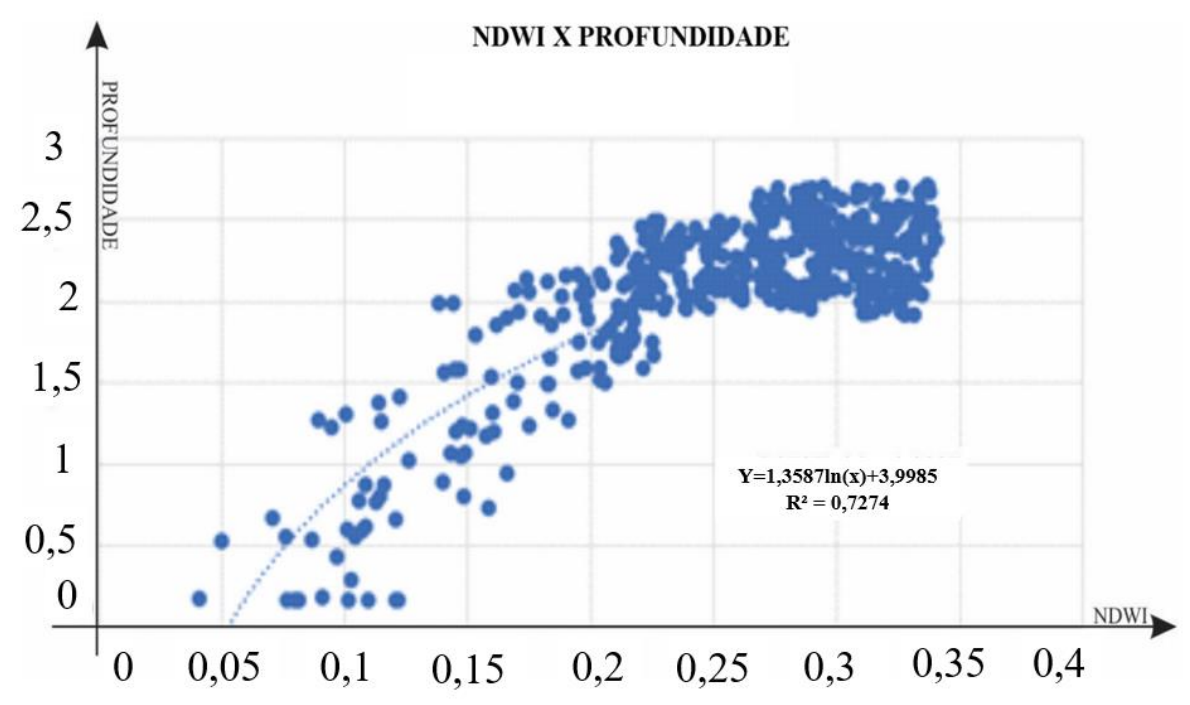

Fonte: os autores (2021).

Assim, utilizando a Equação 3 encontrada com o modelo de regressão, foi possível efetuar a extração da batimetria para cada valor de pixel existente na imagem, correlacionando-o com as coordenadas planialtimétricas e gerando, por conseguinte, a amostra $\mathrm{XYZ}_{\text {espectral. }}$.

$$
Z=1,38587 \ln \ln (N D W I)+3,9985
$$

Sendo o NDWI representado pelo valor do pixel correspondente ao intervalo espectral do verde e do infravermelho próximo.

Mais a diante, com o levantamento batimétrico já executado e os pontos processados, com o intuito de gerar os modelos batimétricos ( $\mathrm{MB}_{\text {bat }} \mathrm{e} \mathrm{MB}_{\text {espectral }}$ ), foi utilizada a ferramenta de krigagem universal, apresentando melhores estimativas para tal conjunto de dados (FERREIRA; RODRIGUES; SANTOS, 2013; ANDRADE et al., 2018; SANTOS et al., 2018). Ressalta-se que a modelagem adequada do semivariograma tem influência direta na interpolação resultante e, dessa forma, essa etapa deve ser realizada com cautela.

Seguidamente, encontraram-se os modelos $\mathrm{MB}_{\text {espectral }}$ e $\mathrm{MB}_{\text {bat }}$ obtidos pela batimetria estimada e pela batimetria de referência obtida por método convencional, respectivamente (Figura 8). 
Figura 8 - Comparação entre os Modelos Digitais de Profundidades.

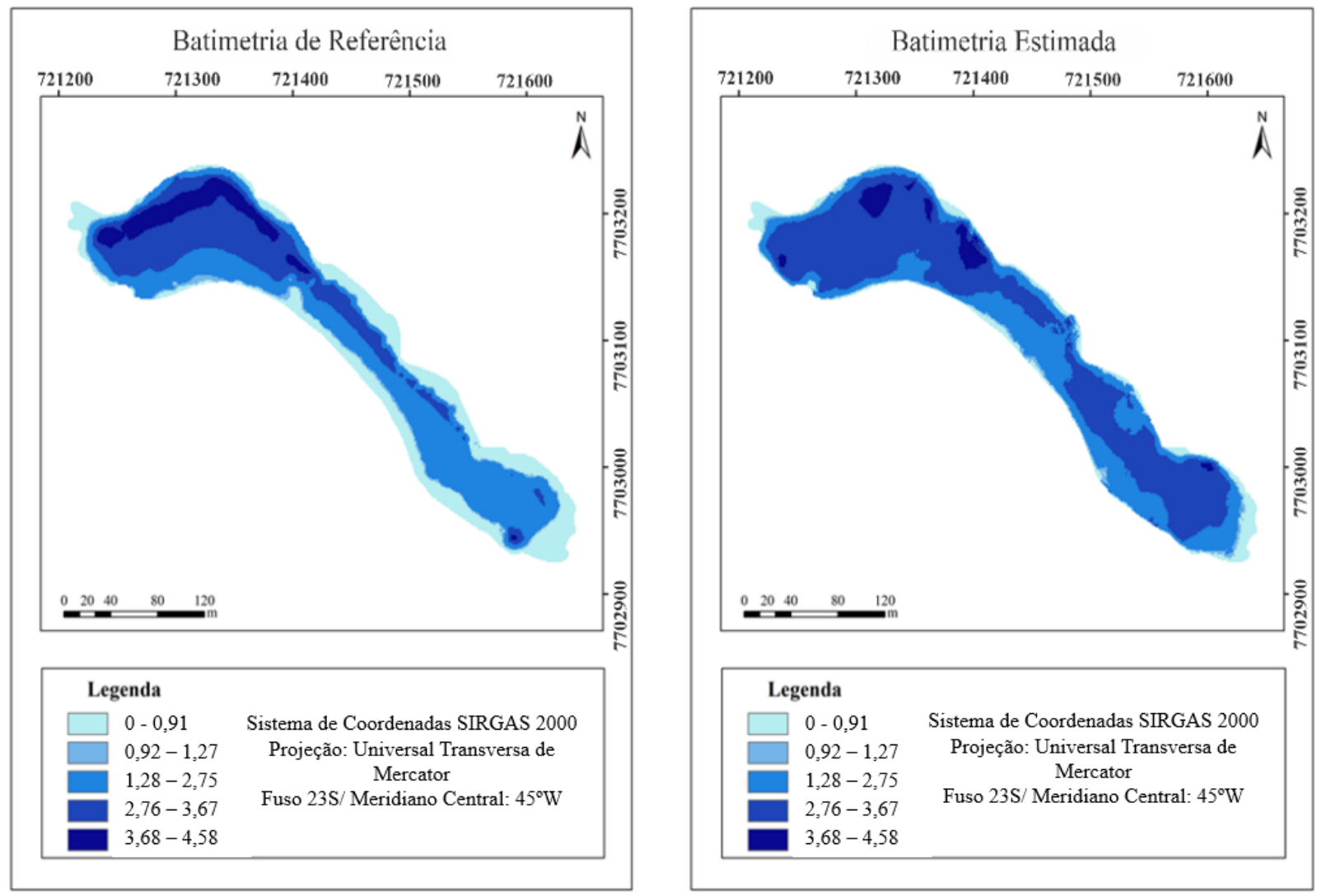

Fonte: Os autores (2021).

Outra comparação pertinente no estudo, consiste na utilização de seções batimétricas por meio de perfis, em que são analisados diferentes pontos de profundidades de referência e a estimada (Figura 9).

Figura 9 - Comparação entre os Modelos Digitais de Profundidades através de perfis.

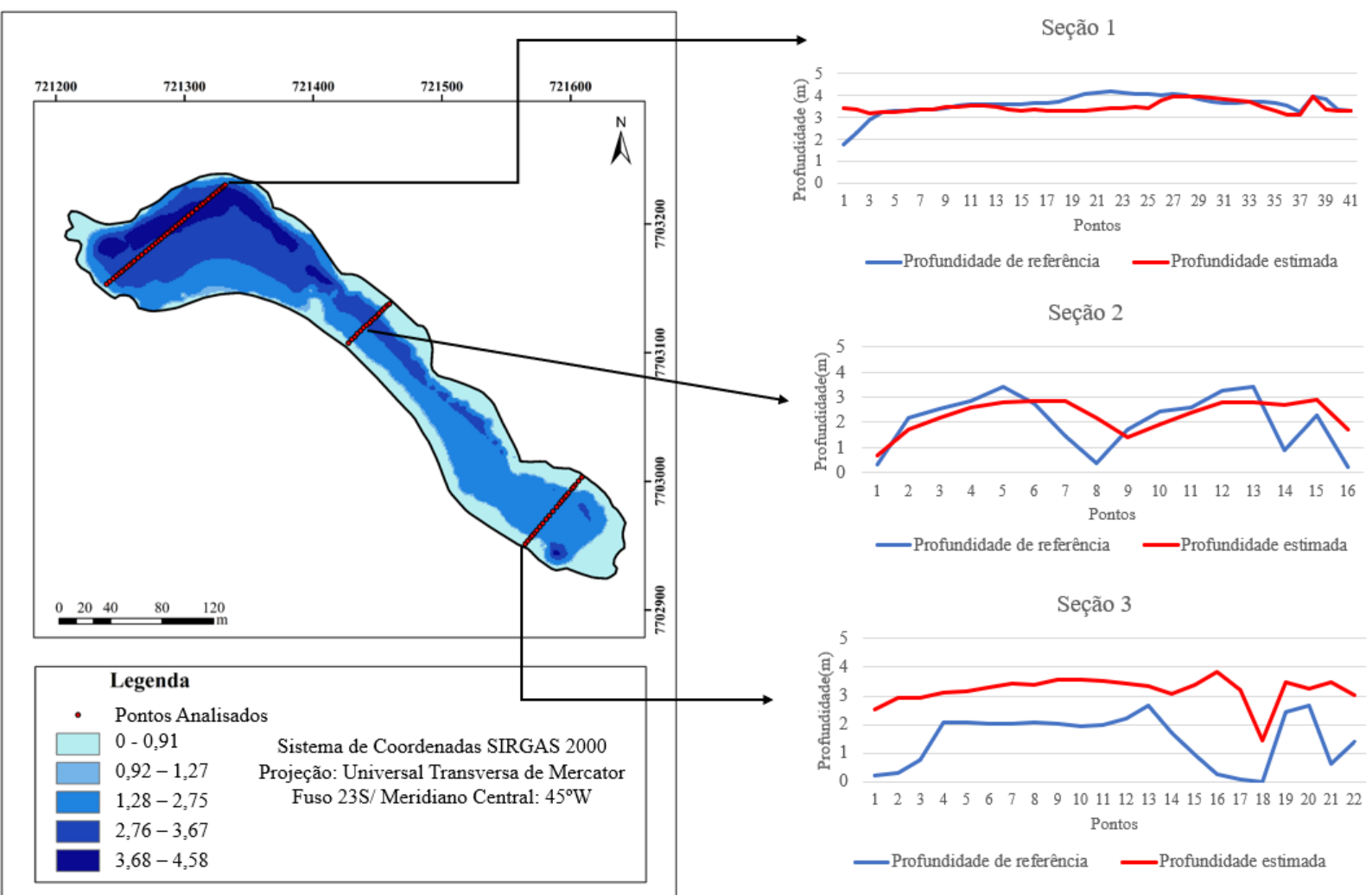

Fonte: Os autores (2021). 
Conforme observado na Figura 9 é possível notar certa variabilidade na profundidade estimada em relação a profundidade de referência, com pequenos deslocamentos. No entanto, existe coerência em pontos de profundidade média ( 1 a 2 metros) e até mesmo profundidas maiores que 3 metros, mostrados na seção 1 .

Com o objetivo de realizar uma análise comparativa dos modelos $\left(\mathrm{MB}_{\text {espectral }} \mathrm{e} \mathrm{MB}_{\text {bat }}\right)$, foram espacializadas as discrepâncias obtidas entre a batimetria de referência e a estimada, por meio de uma subtração entre os MDP's adquiridos (Figura 10).

Figura 10 - Mapa de discrepâncias.

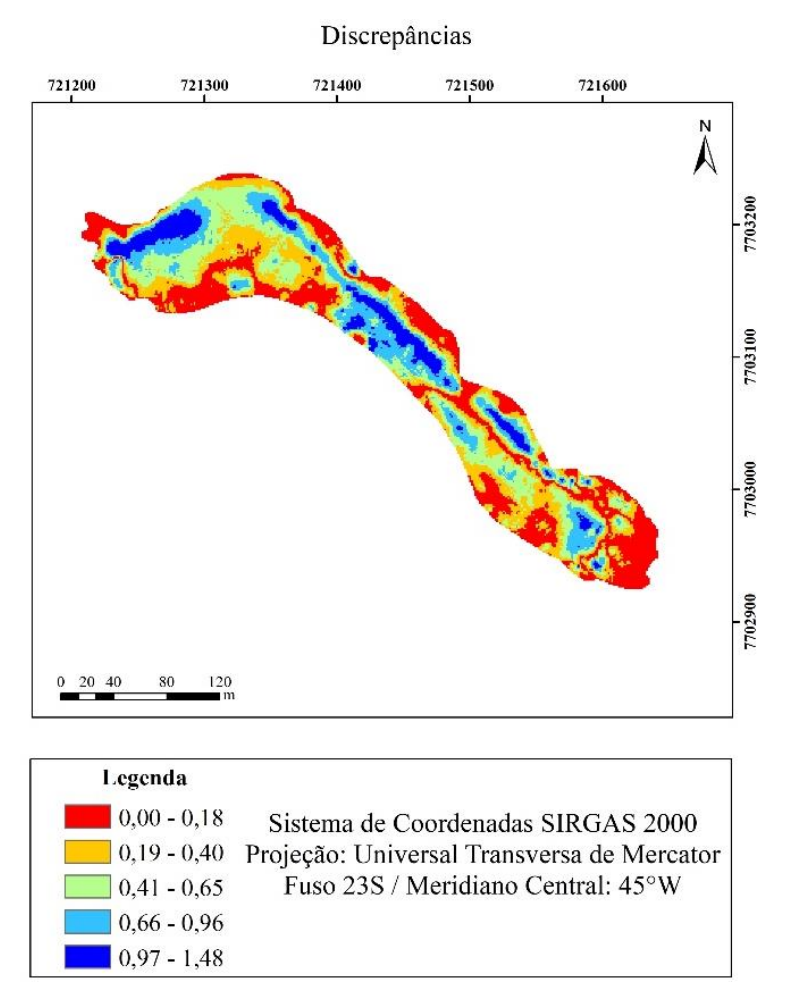

Fonte: Os autores (2021).

De acordo com a Figura 10, as discrepâncias estão em valores absolutos e variam até 1,48 metros, é possível observar que a maior parte dessas discrepâncias encontram-se abaixo de 0,80 m. Outro aspecto importante a ser destacado é o fato dos maiores valores de discrepâncias estarem situados em locais com a presença de vegetação ou de baixa profundidade (como nas bordas), o que já era de se esperar, uma vez que nesses locais existem diversas árvores e demais vegetações que levam a valores de pixels incompatíveis. $\mathrm{O}$ volume encontrado para o $\mathrm{MB}_{\text {espectral }}$ foi de $83606,55 \mathrm{~m}^{3}$, enquanto que para o $\mathrm{MB}_{\text {bat }}$ foi de $81211,77 \mathrm{~m}^{3}$, gerando uma diferença de $2394,78 \mathrm{~m}^{2}$, com um erro de aproximadamente $3 \%$ e evidenciando certa coercitividade nos dados estimados.

Para uma análise mais robusta da qualidade vertical do modelo batimétrico gerado ( $\left.\mathrm{MB}_{\text {espectral }}\right)$, foi empregue o algoritmo MAIB, selecionando todos os pontos de referência (coletados por meio do sistema

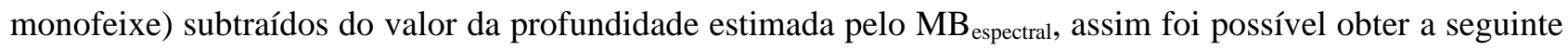
análise exploratória para as discrepâncias (Tabela 2).

Tabela 2 - Análise exploratória das discrepâncias.

\begin{tabular}{c|c}
\hline $\mathbf{N}^{\mathbf{0}}$ de observações & 7443 \\
Média $(\mathbf{m})$ & 0,228 \\
Mínimo (m) & $-1,581$ \\
Máximo (m) & 1,509 \\
Variância (m) & 0,3834 \\
Coeficiente de variação (\%) & 271,39 \\
Coeficiente de curtose & 2,32 \\
Coeficiente de assimetria & $-0,09$ \\
\hline
\end{tabular}


Analisando a Tabela 2, pode-se perceber que o coeficiente de curtose é menor que 3, caracterizando uma distribuição platicúrtica e basicamente simétrica, uma vez que o coeficiente de assimetria indica o desvio em relação a uma distribuição simétrica. Nota-se, também, de acordo com a variância e o coeficiente de variação, que os dados apresentam alta variabilidade (WARRICK; NIELSEN, 1980). Diante do exposto, é possível inferir que os dados tendem a possuir uma distribuição normal.

A seguir, são mostrados alguns gráficos para o auxílio na análise exploratória (Figura 11).

Figura 11 - Análise exploratória espacial.
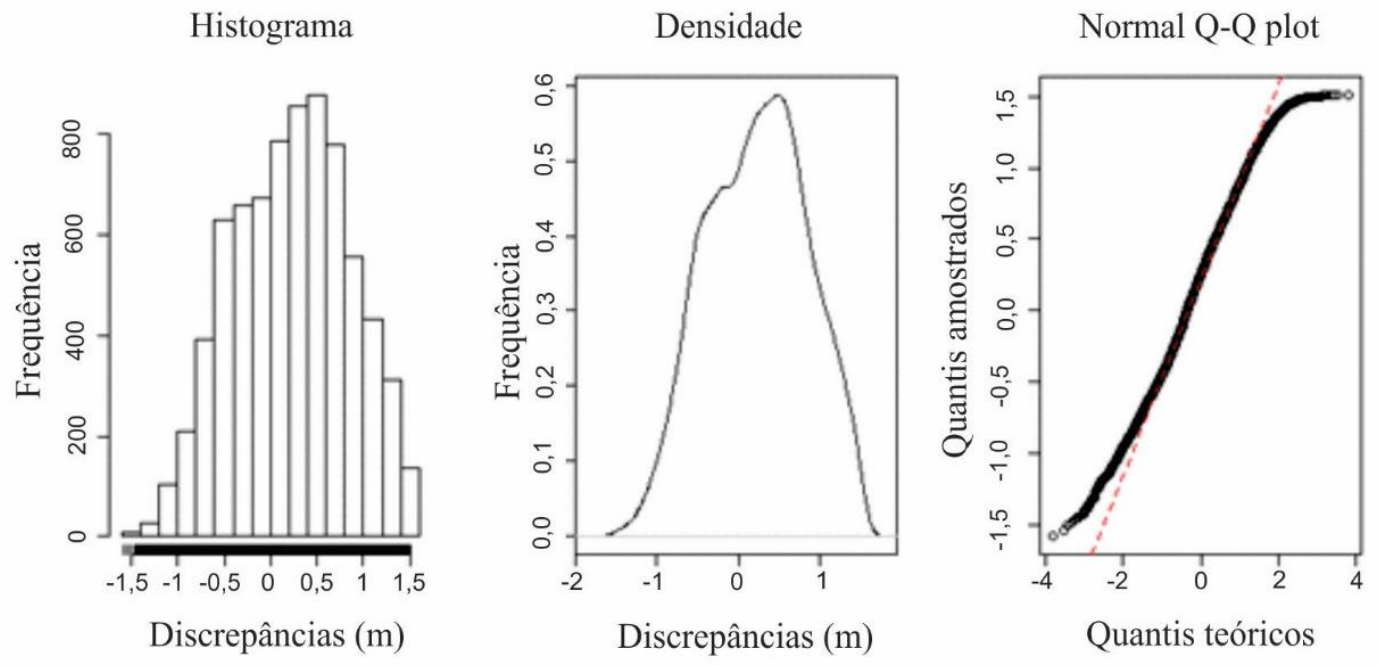

Fonte: Os autores (2021).

Segundo Ferreira (2018), a ferramenta $Q-Q$ Plot destaca-se diante do histograma das discrepâncias e da curva de densidade, pois permite confirmar a adequação da distribuição da frequência dos dados à uma distribuição normal. Após análise gráfica é possível constatar certa normalidade existente nos dados, posto que o gráfico Q-Q Plot apresenta-se como uma linha quase reta (HÖHLE; HÖHLE, 2009).

Dando prosseguimento à execução do algoritmo, para a construção de intervalos de confiança estatisticamente bons é necessário, a priori, examinar a autocorrelação espacial e a distribuição dos dados. De acordo Santos (2015), considera-se que para aplicação dos testes de normalidade univariada, como de ShapiroWilk e Kolmogorov-Smirnov, a amostra deve ser independente espacialmente. Com isso, tem-se que avaliar a autocorrelação espacial da amostra para depois entender, de fato, a normalidade dos dados.

Assim, o próximo passo é a análise de independência por meio do semivariograma experimental (Figura 12), ferramenta da Geoestatística para verificação dessa característica na amostra. Na metodologia utilizada, é realizada a construção de quatro semivariogramas, com alcances iguais a $100 \%, 75 \%, 50 \%$ e $25 \%$ da distância máxima. Através da análise desses gráficos, conclui-se que as discrepâncias são espacialmente dependentes, com uma dependência espacial forte de acordo com a classificação proposta por Cambardella et al. (1994) $\left(\frac{\text { Efeito Pepita }}{\text { Patamar }} \sim 0,25\right)$. 
Figura 12- Semivariograma das discrepâncias para 25\% da distância máxima.

Semivariograma das discrepâncias

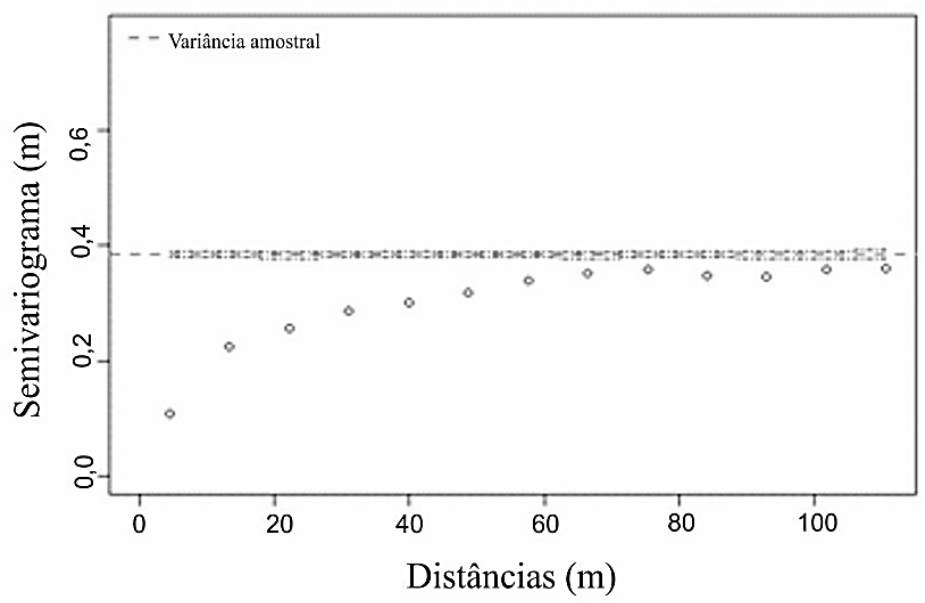

Fonte: Os autores (2021).

Após constatada a dependência dos dados, a próxima etapa seguindo a metodologia proposta é a aplicação do Block Bootstrap para estimativa dos níveis de confiança. Para isso, foi considerado um número de replicações de 5000 vezes, ou seja, a técnica estabelece 5000 novos conjuntos de dados, e 100 como diagonal do bloco, que corresponde ao alcance no semivariograma. A Figura 13 demonstra os histogramas e gráficos $Q-Q$ Plot das amostras construídas para os estimadores $\Phi$ (Incerteza), Root Mean Square Error (RMSE) e $\Phi_{\text {Robusta }}$ (Incerteza Robusta), sendo esse último proposto por Ferreira (2018).

Figura 13 - Histogramas e gráficos Q-Q Plot da amostra Block Bootstrap.
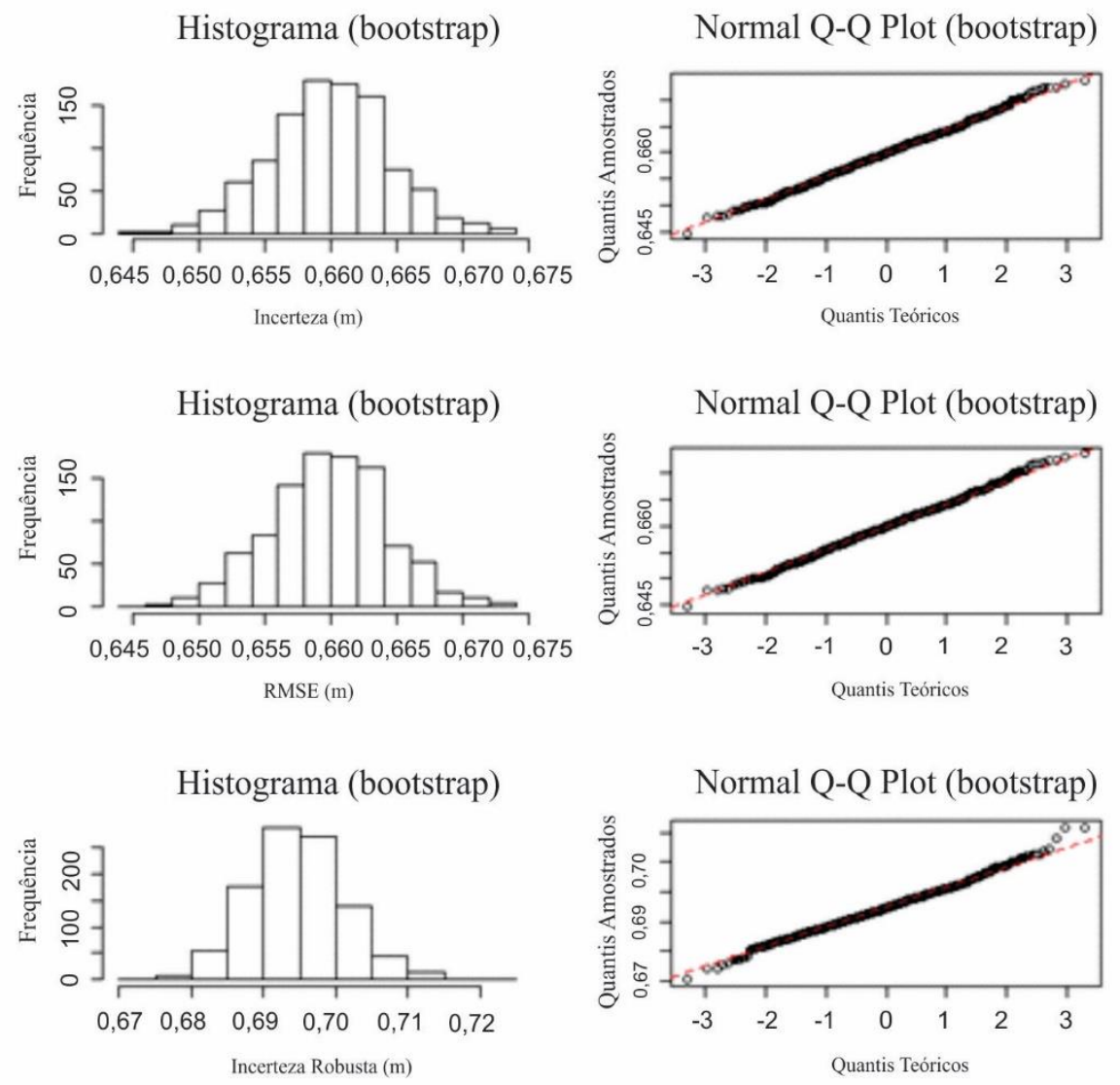

Fonte: Os autores (2021).

É notório que (Figura 13), dentre os três estimadores, a $\Phi_{\text {Robusta }}$ possui uma distribuição com menor grau de normalidade. Todavia, a $\Phi$ e o RMSE mostraram uma variância na casa do centímetro, seguindo a normalidade. Para avaliar as estimativas do Block Bootstrap, foi calculado também o viés da amostra que, 
segundo Ferreira (2018), é determinado através da diferença entre a incerteza estimada por meio da amostra original e a mediana dos dados do Bootstrap (Tabela 3).

Tabela 3 - Incerteza vertical ao nível de confiança de $95 \%$ e viés do Bootstrap.

\begin{tabular}{c|c|c|c}
\hline Estimador & Incerteza Vertical & IC95\% & Viés da amostra \\
\hline RMSE $(\mathrm{m})$ & 0,66 & {$[0,652 ; 0,669]$} & 0,044 \\
$\Phi(\mathrm{m})$ & 0,66 & {$[0,652 ; 0,669]$} & 0,044 \\
$\Phi_{\text {robusta }}$ & 0,73 & {$[0,681 ; 0,709]$} & 0,135 \\
\hline
\end{tabular}

Fonte: Os autores (2021).

As amostras Bootstrap geradas possuem valores baixos para o viés dos estimadores RMSE e $\Phi$. Observa-se também que os intervalos de confiança são bastante estreitos, cerca de $1,5 \mathrm{~cm}$ para o RMSE e $\Phi$.

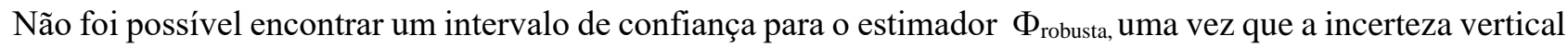
pontual para esse estimador não se encontra dentro do intervalo. Dessa forma, entende-se que os estimadores que melhor representam a variável em questão são o RMSE e o $\Phi$, uma vez que apresentaram menor viés e melhor confiabilidade.

À vista disso, afirma-se que a batimetria estimada com o sensor Micasense possui uma incerteza vertical de aproximadamente $0,6 \mathrm{~cm}$ para os dados em questão. Acredita-se que essa incerteza pode sofrer influência da elevada quantidade de vegetação densa próximo às margens, acarretando valores digitais incompatíveis. Além disso, é importante salientar que a área de estudo não é um corpo d'água límpido e possui uma quantidade de sedimento em suspensão e plantas aquáticas que são notórias nas imagens pré-processadas. Vale ressaltar que para diferentes reservatórios, respostas díspares podem ser encontradas, em virtude das taxas distintas de componentes opticamente ativos, como a matéria orgânica dissolvida, fitoplâncton e sedimentos minerais e orgânicos, que interagem com a radiação solar de uma forma dependente da proporção existente no local.

\section{CONCLUSÕES}

No presente trabalho realizou-se a estimativa da batimetria com a utilização do sensor multiespectral Micasense acoplada a um RPA. Ainda, foi verificada a qualidade do produto obtido de forma qualitativa e quantitativa por meio do algoritmo MAIB. O resultado encontrado com o novo sensor evidenciou uma melhora considerável, com redução na incerteza vertical de $0,14 \mathrm{~m}$ em relação ao estudo feito por Andrade et al. (2020). Comprovou, também, a aplicabilidade da técnica para estudos de cunho ambiental, solicitação de outorgas e análises relativas entre modelos para acompanhamento de processo de assoreamento, por exemplo.

No entanto, é necessário pontuar diversas limitações para o método, dentre elas, a utilização em águas com baixa quantidade de sedimentos em suspensão e pouco profundas (uma vez que a luz perde capacidade de penetração com o aumento da coluna de água), concomitantemente a uma morfologia submersa com pouca movimentação. Em relação à execução do aerolevantamento, recomenda-se que o voo seja realizado em dias ensolarados e em horários não muito distantes do zênite solar. Outro ponto importante a se destacar é a realização do voo próximo à data do levantamento batimétrico, uma vez que, dependendo do reservatório a ser estudado, a alteração da morfologia de fundo pode influenciar na qualidade dos dados estimados.

O uso de RPA's no âmbito cartográfico é algo crescente nos últimos anos, já que essa tecnologia possui um tempo de execução reduzido e baixo custo se comparado ao levantamento batimétrico tradicional. No entanto, ainda necessita-se de mais testes em diferentes áreas com características particulares. Salienta-se, também, que o processamento e análise das áreas deve ser executado com cuidado pelo examinador.

Contudo, é importante lembrar que para a realização de projetos que necessitem de um grau de exatidão maior, é recomendado a utilização do levantamento batimétrico convencional, uma vez que esse é realizado com maior controle de campo e por conseguinte, maior controle das incertezas.

Assim, pode-se concluir que a utilização de um sensor mais completo e confiável torna a estimativa da batimetria algo muito mais próximo do real, o que permite a criação de um modelo mais fidedigno para 
estudos ambientais ou estudos preliminares sobre a morfologia submersa e movimentação de sedimentos em locais de águas rasas com baixa quantidade de materiais em suspensão e plantas aquáticas.

\section{Agradecimentos}

Os autores agradecem ao GEPLH (Grupo de Estudo e Pesquisa em Levantamentos Hidrográficos) e ao PIBIC/CNPq (Programa Institucional de Bolsas de Iniciação Científica/Conselho Nacional de Desenvolvimento Científico e Tecnológico - No de Registro dos Projetos: 10764272967 e 10764274441 ) pelo apoio e contribuição no desenvolvimento desta pesquisa.

\section{Contribuição dos Autores}

As contribuições dos autores no desenvolvimento deste trabalho são: curadoria dos dados, investigação, metodologia e redação - minuta inicial, supervisão, Laura Coelho de Andrade; metodologia, visualização e redação - revisão e edição, Italo Oliveira Ferreira; visualização e redação - revisão e edição, Nilcilene das Graças Medeiros; visualização e edição, Victória Gibrim Teixeira e visualização e edição, Felipe Catão Mesquita Santos

\section{Conflitos de Interesse}

Os autores declaram que não há conflitos de interesse.

\section{Referências}

AGISOFT, L. L. C. Agisoft metashape user manual, Professional edition, Version 1.5. Agisoft LLC, St. Petersburg, Russia. 2018. Disponível em: 〈https://www. agisoft. com/pdf/metashape-pro_1_5_en. pdf〉. Acesso em: 20 mai. 2020.

ANEEL - ANA (Agência Nacional de Energia Elétrica - Agência Nacional de Águas). Resolução Conjunta $n^{0}$ 003: Estabelecer as condições e os procedimentos a serem observados pelos concessionários e autorizados de geração de energia hidrelétrica para a instalação, operação e manutenção de estações hidrométricas visando ao monitoramento pluviométrico, linimétrico, fluviométrico, sedimentométrico e de qualidade da água associado a aproveitamentos hidrelétricos, e dar outras providências. Brasília - DF, 10 de agosto de 2010.

ANDRADE, L.C.; FERREIRA, Í.O.; MEDEIROS, N.G.; FONSECA, I.G.R. Viabilidade do uso de imagens de RPA's para extração da batimetria em reservatórios de água rasos. GEOPROCESSAMENTO APLICADO À ANÁLISE DE AMBIENTE. 1ed. Editora Unesc, 2020. DOI. 10.18616/geop06

ANDRADE, L.C.; FERREIRA, Í.O.; SANTOS, F.C.M.; OLIVEIRA, J.C. Avaliação de interpoladores probabilísticos para melhor gestão hídrica de corpos d'água. In: VII SIMPÓSIO BRASILEIRO DE CIÊNCIAS GEODÉSICAS E TECNOLOGIAS DA GEOINFORMAÇÃO,2018. Anais... Recife. 2018. v.1. pp.172-181.

ANNADURAI, M. Assessment of surface water dynamicsin bangalore using wri, ndwi, mndwi. Supervised classification and k-t transformation. Aquatic Procedia, v. 4, p. 739-746, 2015. DOI. 10.1016/j.aqpro.2015.02.095

ASHLEY, G. M., CUTHBERT, M. O., GLEESON, T. P., REYNOLDS, S. R., BENNETT, M. R., NEWTON, A. C., \& MCCORMACK, C. J. Hydrologic and Agent-based Modelling of Hydro-refugia in East Africa, Insights into the Importance of Water Resources in Hominin Evolution and Dispersal. In: AGU Fall Meeting Abstracts. p. PP11F-10, 2017.

BATISTA, F. F. Influência dos modelos de dependência espacial na definição de mapas temáticos. Dissertação (Mestrado). Programa de Pós-Graduação em Estatística Aplicada e Biometria. Universidade Federal de Viçosa, Viçosa, Minas Gerais, 2012. 
BELSLEY, D. A.; KUH, E.; WELSCH, R. E. Regression diagnostisc: Identifying inflential data ans sources of collinearity. New York: John Willey \& Son. 1980.

CAMARGO, E. C. G. Geoestatística: Fundamento e Aplicações. In: CAMARA, G.; MEDEIROS, J. S. Geoprocessamento em Projetos Ambientais. $2^{a}$ ed. São José dos Campos: INPE, 1998. Cap 5, 36p.

CAMBARDELlA, C. A.; MOORMAN, T. B.; NOVAK, J. M.; PARKIN, T. B.; KARLEN, D. L.; TURCO, R. F.; KONOPKA, A. E. Field scale variability of soil properties in Central Iowa soils. Soil Science Society of America Journal, Madison, v. 58, n. 5, p. 1501-1511, 1994. DOI. 10.2136/sssaj1994.03615995005800050033x

CANCIAM, C. A. Predição do coeficiente de expansão térmica do óleo de girassol através da aplicação da análise de regressão linear. Revista Brasileira de Tecnologia Agroindustrial, v. 6, n. 2, p. 852-863, 2012. DOI. 10.3895/S1981-36862012000200011

COELHO, L.; BRITO, J. N. Fotogrametria digital. Editora da Universidade do Estado do Rio de Janeiro (EdUERJ), 2007.196p.

COLLISCHONN, B.; CLARKE, R. T. Estimativa e incerteza de curvas cota-volume por meio de sensoriamento remoto. RBRH, v. 21, n. 4, p. 719-727, 2016. DOI. 10.1590/2318-0331.011616022

CRÓSTA, A. P. Processamento digital de imagens de sensoriamento remoto. UNICAMP/Instituto de Geociências, 1999.

DESKTOP, ESRI ArcGIS. version 10.5. 1. ESRI: Redlands, CA, USA, 2019.

DRAPER, N.R.; SMITH, H. Applied regression analysis. 2. ed. New York: John Wiley and Sons, 1981.

ELLMER, W.; ANDERSEN, R. C.; FLATMAN, A.; MONONEN, J.; OLSSON, U.; ÖIÅS, H. Feasibility Of Laser Bathymetry For Hydrographic Surveys On The Baltic Sea. The International Hydrographic Review, n. 12, p. 33-50, 2014.

FERREIRA, I. O.; RODRIGUES, D. D.; SANTOS, G. R. Estudo Sobre a Utilização Adequada da Krigagem na Representação Computacional de Superfícies Batimétricas. Revista Brasileira de Cartografia, Rio de Janeiro, v. 64, n. 5, p.831-842, 2013.

FERREIRA, Í. O.; RODRIGUES, D. D.; SANTOS, G. R.; Coleta, Processamento E Análise De Dados Batimétricos. $1^{\text {a }}$ Ed. Saarbrucken: Novas Edições Acadêmicas, V. 1, 100P., 2015.

FERREIRA, Í. O., ZANETTI, J., GRIPP, J. S., \& MEDEIROS, N.G. Viabilidade do uso de imagens do sistema Rapideye na determinação da batimetria de águas rasas. Revista Brasileira de Cartografia, v. 68, n. 7 , 2016.

FERREIRA, Í.O.; AYRES NETO, A.; MONTEIRO, C. S. O Uso De Embarcações Não Tripuladas Em Levantamentos Batimétricos. Revista Brasileira De Cartografia, v. 68, N. 10, 2016.

FERREIRA, I. O. Controle de qualidade em levantamentos hidrográficos. Tese (Doutorado). Programa de Pós-Graduação em Engenharia Civil, Departamento de Engenharia Civil, Universidade Federal de Viçosa, Viçosa, Minas Gerais, 216p., 2018.

FERREIRA, I. O.; EMILIANO, P. C.; SANTOS, A. D. P.; MEDEIROS, N. G.; OLIVEIRA, J. C. Proposição De Um Estimador Pontual Para Incerteza Vertical De Levantamentos Hidrográficos. Revista Brasileira de Cartografia,vol. 71, n.1, 2019. pp.1-30. DOI. 10.14393/rbcv71n1-44096

FOERSTNOW, L. P. \& MENEZES, J. T. Aplicabilidade de imagens de satélite utilizando NDWI na determinação da batimetria da Lagoa da Conceição, Florianópolis, SC. In: SIMPÓSIO BRASILEIRO DE SENSORIAMENTO REMOTO, 2011, Curitiba. Anais... Curitiba: XV-SBSR. 2011. p. 4397-4404.

GIORDANO, F.; MATTEI, G.; PARENTE, C.; PELUSO, F.; SANTAMARIA, R. Integrating Sensors Into A Marine Drone For Bathymetric 3d Surveys In Shallow Waters. Sensors, v. 16, N. 1,. 41, 2015.

GUENTHER, G. C.; THOMAS, R. W. L.; LAROCQUE, P. E. Design Considerations For Achieving High Accuracy With The Shoals Bathymetric Lidar System. In: Cis Selected Papers: Laser Remote Sensing Of Natural Waters-From Theory To Practice. International Society For Optics And Photonics, P. 54-71, 1996. DOI. 10.1117/12.258353 
HÖHLE, J.; HÖHLE, M. Accuracy Assessment Of Digital Elevation Models By Means Of Robust Statistical Methods. ISPRS Journal Of Photogrammetry And Remote Sensing, v. 64, n. 4, p. 398-406, 2009. DOI. 10.1016/j.isprsjprs.2009.02.003

IHO-International Hydrographic Organization. C-13: IHO Manual On Hydrography. Mônaco: International Hydrographic Bureau,2005, 540p.

IHO-International Hydrographic Organization. S-44: IHO Standards for Hydrographic Surveys. Special Publication n. 44-5th. Mônaco: International Hydrographic Bureau, 36p., 2008.

JONG, C.D.; LACHAPELLE, G.; SKONE, S.; ELEMA, I.A. Hydrography. $2^{\text {a }}$ Ed. Delft University Press: Vssd, p. 354, 2010.

KRUG, L. A.; NOERNBERG, M. A. O sensoriamento remoto como ferramenta para determinação de batimetria de baixios na Baía das Laranjeiras, Paranaguá-PR. Revista Brasileira de Geofísica, v. 25, p. 101-105, 2007. DOI. 10.1590/S0102-261X2007000500010

LI, W.; Du, Z.; Ling, F.; Zhou, D.; Wang, H.; Gui, Y.; Sun, B.; Zhang, X. A Comparison Of Land Surface Water Mapping using the normalized difference water index from TM, ETM+ and Ali. Remote Sensing. v.5, n 11, p.5530-5549,2013. DOI. 10.3390/rs5115530

LEBOURGEOIS, V., BEGUE A., MARTINE J. Sensitivity of airborne-derived crop stress indices to the agricultural pratices. In: International Conference on Agricultural Engineering and Industry Exhibition (AgEng), 08., 2008, Hersonissos. Anais... Creta, 2008. p. 1-13.

LYZENGA, D. R. Passive remote sensing techniques for mapping water depth and bottom features. Applied Optics. V.17, n. 3, p. 379-383, 1978. DOI. 10.1364/AO.17.000379

MANLEY, J. E. Unmanned surface vehicles, 15 years of development. In: OCEANS 2008, IEEE, p.1-4,2008. DOI. 10.1109/oceans.2008.5152052

MCFEETERS, S. K. The use of the Normalized Difference Water Index (NDWI) in the delineation of open water features. International Journal of Remote Sensing, v. 17, n. 7, p. 1425-1432, 1996. DOI. 10.1080/01431169608948714

MICASENSE. RedEdge-MX Specifications. Disponível em: <https://micasense.com/rededge-mx/wpcontent/uploads/2019/11/RedEdge-MX-Specifications.pdf>. Acesso em: 08 mai. 2020.

MENESES, P; ALMEIDA, T. Introdução ao processamento de imagens de sensoriamento remoto. 1 ed. Brasília: UnB/CNPq, v.1, 266p., 2012.

NEITZEL, F., KLONOWSKI, J. Mobile 3D mapping with a low-cost UAV system. Proceedings of the International Conference on Unmanned Aerial Vehicle in Geomatics, Vol. 38, Zurich, Switzerland, 2011.

OLIVEIRA, L. T. Processamento de Imagens Obtidas por Drones. DroneShow Latin America. Anais... São Paulo, SP. 2017.

PASTOL, Y. Use Of Airborne Lidar Bathymetry For Coastal Hydrographic Surveying: The French Experience. Journal Of Coastal Research. N. 62, P. 6-18, 2011.

PHILPOT, W. D. Bathymetric mapping with passive multispectral imagery. Applied Optics. V. 28, n. 8, p. 1569-1578, 1989.

POLIDORIO, A. M., FRANCO, C., IMAI, N. N., TOMMASELli, A. M. G., \& GALO, M. D. L. B. T. Correção radiométrica de imagens multiespectrais CBERS e Landsat ETM usando atributos de reflectância e de cor. In: Simpósio Brasileiro de Sensoriamento Remoto (SBSR), n. 12, 2005. Anais... Goiânia, 2005. p. 4241-4248.

R CORE TEAM. R: A language and environment for statistical computing. R Foundation for Statistical Computing, Vienna, Austria. Disponível em:<https://www.Rproject.org/.2020> Acesso em: 15 abr. 2020.

REBOUÇAS, A. C. Água doce no mundo e no Brasil. In: BRAGA, B; TUNDISI, J. G.; MATSUMURATUNSISI, T.; CIMINELLI, V. S. T. Águas doces no Brasil: capital ecológico, uso e conservação. 4. ed. São Paulo: Escrituras Editora, n. 4, p. 729, 2015.

ROTUNNO FILHO, M; ZEILHOFER, P. Modelagem da Poluição não Pontual na Bacia do Rio Cuiabá 
Baseada em Geoprocessamento. RBRH - Revista Brasileira de Recursos Hídricos, v. 8 n. 4, p. 115$135,2003$.

SANTOS, A. P.2015. Controle de qualidade cartográfica: metodologias para avaliação da acurácia posicional em dados espaciais. Tese (Doutorado). Programa de Pós-Graduação em Engenharia Civil, Departamento de Engenharia Civil, Universidade Federal de Viçosa, Viçosa, Minas Gerais, 172p.

SANTOS, F. C. M.; FERREIRA, I. O.; ANASTACIO, L. C.; OLIVEIRA, J. C. Emprego do sensoriamento remoto ótico para estimativa do assoreamento de reservatórios de água. In: Simpósio Brasileiro de Ciências Geodésicas e Tecnologias da Geoinfomação, 2018, Recife. Anais... Recife. 2018. v. 1. p. 936-944.

SCHENK, T. Introduction to photogrammetry. The Ohio State University, Columbus, v. 106, 2005.

SEBER, G.A.F. Linear regression. New York: John Wiley and Sons, 1977.

TEDESCO, A; CENTENO J.A.S. Utilização de imagens Ikonos para estimativa de profundidades. COLÓQUIO BRASILEIRO DE CIÊNCIAS GEODÉSICAS, III, Curitiba, PR, 2003. Anais... Curitiba: Universidade Federal do Paraná. 2003.

VIEIRA, S. R. Geoestatística em estudos de variabilidade espacial do solo. In: NOVAES, R. F.; ALVAREZ V., V. H.; SCHAEFER, C. E G. R. Tópicos em ciências do solo. Viçosa, MG: Sociedade Brasileira de Ciência do Solo, v.1. p.2-54, 2000.

WARRICK, A.W.; NIELSEN, D.R. Spatial variability of soil physical properties in the field. In: HILLEL, D. Applications of soil physics. New York: Academic Press, p.319-344, 1980.

WOLF, P. R. Elements of Photogrammetry, McGraw-Hill Book Company, Singapure, 1983.

WOLF, P.R. \& DEWITT, B.A. Elements of Photogrammetry with Applications in GIS. 3rd Edition. 2000.

\section{Biografia do autor principal}

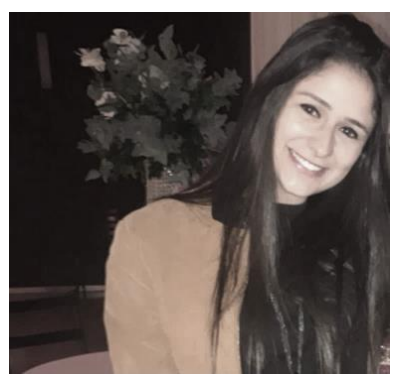

Laura Coelho de Andrade, natural de Ubá, MG - Brasil, nasceu em 05 de julho de 1998, é Engenheira Agrimensora e Cartógrafa, mestranda em Engenharia Civil, na área de concentração em Informações Espaciais (Geodésia e Hidrografia) pela Universidade Federal de Viçosa (UFV). Já foi bolsista de iniciação científica da Funarbe e do CNPq nos anos de 2018 a 2020, atuando principalmente na área de Levantamentos Hidrográficos. Atualmente é membro do Grupo de Estudo e Pesquisa em Levantamentos Hidrográficos (GEPLH-UFV) e possui experiência nas áreas de Batimetria por Resposta Espectral e Modelagem Tridimensional.

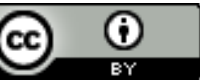

Esta obra está licenciada com uma Licença Creative Commons Atribuição 4.0 Internacional - CC BY. Esta licença permite que outros distribuam, remixem, adaptem e criem a partir do seu trabalho, mesmo para fins comerciais, desde que lhe atribuam o devido crédito pela criação original. 